\title{
Disruption of Glucagon-Like Peptide 1 Signaling in Sim 1 Neurons Reduces Physiological and Behavioral Reactivity to Acute and Chronic Stress
}

\author{
Sriparna Ghosal, ${ }^{1,2}{ }^{\circledR}$ Amy E.B. Packard, ${ }^{1}$ Parinaz Mahbod, ${ }^{1}$ Jessica M. McKlveen, ${ }^{1,3}$ Randy J. Seeley, ${ }^{4}$ Brent Myers, ${ }^{1}$ \\ Yvonne Ulrich-Lai, ${ }^{1}$ Eric P. Smith, ${ }^{5}{ }^{\circ}$ David A. D'Alessio, ${ }^{6}$ and James P. Herman ${ }^{1}$ \\ ${ }^{1}$ Department of Psychiatry and Behavioral Neuroscience, University of Cincinnati, Cincinnati, Ohio 45237, ${ }^{2}$ Department of Psychiatry and Neurobiology, \\ Yale School of Medicine, New Haven, Connecticut 06508, ${ }^{3}$ Department of Pharmacology, University of North Carolina, Chapel Hill, North Carolina 27599, \\ ${ }^{4}$ Department of Surgery, University of Michigan, Ann Arbor, Michigan 48109, ${ }^{5}$ Department of Internal Medicine, University of Cincinnati, Cincinnati, Ohio \\ 45237, and ${ }^{6}$ Duke Molecular Physiology Institute, Duke University, Durham, North Carolina 27701
}

Organismal stress initiates a tightly orchestrated set of responses involving complex physiological and neurocognitive systems. Here, we present evidence for glucagon-like peptide 1 (GLP-1)-mediated paraventricular hypothalamic circuit coordinating the global stress response. The GLP-1 receptor (Glp1r) in mice was knocked down in neurons expressing single-minded 1, a transcription factor abundantly expressed in the paraventricular nucleus (PVN) of the hypothalamus. Mice with single-minded 1-mediated Glp1r knockdown had reduced hypothalamic-pituitary-adrenal axis responses to both acute and chronic stress and were protected against weight loss associated with chronic stress. In addition, regional Glp1r knockdown attenuated stress-induced cardiovascular responses accompanied by decreased sympathetic drive to the heart. Finally, Glp1r knockdown reduced anxiety-like behavior, implicating PVN GLP-1 signaling in behavioral stress reactivity. Collectively, these findings support a circuit whereby brainstem GLP-1 activates PVN signaling to mount an appropriate whole-organism response to stress. These results raise the possibility that dysfunction of this system may contribute to stress-related pathologies, and thereby provide a novel target for intervention.

Key words: acute stress; blood pressure; chronic stress; elevated plus maze; heart rate; HPA axis

Significance Statement

Dysfunctional stress responses are linked to a number of somatic and psychiatric diseases, emphasizing the importance of precise neuronal control of effector pathways. Pharmacological evidence suggests a role for glucagon-like peptide-1 (GLP-1) in modulating stress responses. Using a targeted knockdown of the GLP-1 receptor in the single-minded 1 neurons, we show dependence of paraventricular nucleus GLP-1 signaling in the coordination of neuroendocrine, autonomic, and behavioral responses to acute and chronic stress. To our knowledge, this is the first direct demonstration of an obligate brainstem-to-hypothalamus circuit orchestrating general stress excitation across multiple effector systems. These findings provide novel information regarding signaling pathways coordinating central control of whole-body stress reactivity.

\section{Introduction}

Stress-related information is received and integrated in the brain, which activates adaptive (behavioral and physiological) responses to restore or maintain homeostasis. Dysfunction of stress adaptation can contribute to a variety of pathological conditions

This work was supported by National Institute of Mental Health R01MH069860 to J.P.H., American Heart Association AHA13PRE17100141 to S.G., and the Albert J. Ryan Foundation. We thank the entire J.P.H. laboratory for help with the experiments and critical discussions.
(Chrousos and Gold, 1992; de Kloet et al., 2005; Grippo, 2009). Despite a wealth of data linking stress and disease, the neural pathways underpinning these connections are only gradually becoming understood. Physiological responses to stressors cause rapid activation of the sympathetic nervous system and promote

R.J.S. serves on scientific advisory boards for Daiichi Sankyo, Novo Nordisk, Novartis, Nestle, Takeda, Boehringe Ingelheim, and Sanofi, and receives research support from Novo Nordisk, Ethicon Endo-Surgery, Boehringer Ingelheim, Janssen/Johnson \& Johnson, and Sanofi. The remaining authors declare no competing financial interests.

Correspondence should be addressed to Dr. James P. Herman, 2170 East Galbraith Road ML 0506, Cincinnati, $0 \mathrm{H}$ 45237. E-mail: james.herman@uc.edu.

DOI:10.1523/JNEUROSCI.1104-16.2016

Copyright $\odot 2017$ the authors $\quad 0270-6474 / 17 / 370184-10 \$ 15.00 / 0$ 
glucocorticoid hormone release by the hypothalamic-pituitaryadrenocortical (HPA) axis (Ulrich-Lai and Herman, 2009). Stress-induced activation of the sympathetic nervous system rapidly increases heart rate (HR) and blood pressure (among other effects) (Carter and Goldstein, 2015). The HPA axis response is initiated by corticotropin-releasing hormone neurons of the hypothalamic paraventricular nucleus (PVN), which stimulate ACTH release and consequent secretion of glucocorticoids by the adrenal glands (Herman et al., 2016). These systems, both provoked by stress, act in a mutual and coordinated fashion to mobilize central and peripheral energetic resources over both immediate and extended periods of time, allowing reaction to or anticipation of threat and recovery of homeostasis (Ulrich-Lai and Herman, 2009).

Recently, glucagon-like peptide 1 (GLP-1) has been hypothesized to be an important component of brain mechanisms regulating stress adaptation (Ghosal et al., 2013). Although originally identified as a gastrointestinal hormone (Varndell et al., 1985), GLP-1 is also produced in the brain by neurons largely confined to the caudal division of the nucleus of the solitary tract (NTS) and the ventral medulla (Merchenthaler et al., 1999). Importantly, the GLP-1 receptor (Glp1r) is abundantly expressed in the PVN (Merchenthaler et al., 1999), and GLP-1-immunoreactive fibers derived from the NTS innervate both neuroendocrine and preautonomic PVN neurons (Vrang et al., 2007; Tauchi et al., 2008), suggesting possible involvement in stress reactivity. Indeed, pharmacological studies demonstrate that GLP-1 receptor antagonism reduces HPA axis responses to both reactive (physical) and anticipatory (emotional) stressors (Kinzig et al., 2003), and central administration of GLP-1 receptor agonists activates hypothalamic and brainstem neurons innervating sympathetic preganglionic neurons (Yamamoto et al., 2002, 2003). The clear interaction between HPA- and sympatho-excitatory NTS GLP-1 projections and putative PVN stress effector neurons led us to hypothesize that endogenous GLP-1 neurons form a dedicated neurocircuit coordinating different modalities of stress responses at the level of the PVN. To address this hypothesis, we developed a mouse model with targeted knockdown (KD) of Glp1r in the single-minded 1 (Sim1)-expressing neurons. Our findings demonstrate that Sim1-mediated KD of the Glp1r in the PVN of the hypothalamus is required for neuroendocrine, sympathetic, and behavioral responses to stressors of both physical and emotional origin, consistent with a critical role for NTS GLP-1 neurons in driving the whole-organism response to stress.

\section{Materials and Methods}

Animals. Sim-1-Cre; Glp1r ${ }^{\mathrm{f} / \mathrm{f}}$ mice were generated by crossing Glp $1 r^{\mathrm{f} / \mathrm{f}}$ mice (Smith et al., 2014) with Sim1-Cre mice (Balthasar et al., 2005), a kind gift from Dr. J. Elmquist (University of Texas Southwestern Medical Center, Dallas). To generate litters that contained both genotypes (Sim1Cre, Glp $1 r^{\mathrm{f} / \mathrm{f}}$ and $\left.G l p 1 r^{\mathrm{f} / \mathrm{f}}\right)$, the dams were $G l p 1 r^{\mathrm{f} / \mathrm{f}}$ and the sires were Glp1 $r^{\mathrm{f} / \mathrm{f}}$ mice heterozygous for the Sim1-Cre transgene. The experiments reported here were performed on 10- to 12-week-old male Sim-1-Cre; Glp1r $r^{\mathrm{f} / \mathrm{f}}$ (homozygous for Glp1r flox [Glp1r ${ }^{\mathrm{f} / \mathrm{f}]}$ and expressing Sim1-Cre and littermate Glp1 ${ }^{\mathrm{f} / \mathrm{f}}$ [Control] mice). To test for possible effects of the Sim1-Cre transgene on stress outcomes, Sim1-Cre and wild-type littermates were generated by crossing Sim1-Cre male and wild-type (wt) C57BL/6 female mice (Harlan Laboratories). Experiments reported were performed on 10- to 12-week-old male Sim-1-Cre and littermate wt mice. Mice were housed in a temperature-controlled facility on a $12 \mathrm{~h}$ light/ dark schedule (lights on at $0600 \mathrm{~h}$ ) unless otherwise noted. Mice were fed either standard rodent chow (Harlan Laboratories; $3.1 \mathrm{kcal} / \mathrm{g} ; ~ 5 \%$ fat) or a high-fat diet (Research Diets; $4.54 \mathrm{kcal} / \mathrm{g} ; \sim 40 \%$ fat) as appropriate. Food and water were provided ad libitum unless otherwise noted. All experiments were approved by the University of Cincinnati Institutional Animal Care and Use Committee and were performed in accordance with the NIH Guide for the care and use of laboratory animals.

RNA isolation and quantitative PCR expression analysis. RNA extraction and real-time PCR were performed as previously described (Smith et al., 2014). Briefly, mice ( $n=4$ or 5 per group) were rapidly decapitated and the brains removed and flash-frozen in dry ice-chilled isopentane. The brain regions were dissected from flash-frozen brains in the cryostat (Microm HM550MP) at $-16^{\circ} \mathrm{C}$ on the day of RNA extraction using microdissection method. Brains were placed on cooled metal block in the cryostat, areas of interest identified based on morphological landmarks and coronal sections cut at a thickness of $500 \mu \mathrm{m}$. Sections were mounted on a chilled slide and bilateral tissue punches obtained using a microdissection needle with a diameter of $0.5 \mathrm{~mm}$. Targeted regions included areas known to (1) express Glp1r and/or Sim1 and (2) have putative involvement in stress processing. Tissues collected included the entire rostral to caudal extent of PVN (anterior margin: bregma $-0.58 \mathrm{~mm}$, posterior margin: bregma $-1.08 \mathrm{~mm}$ ); the arcuate nucleus (anterior margin: bregma $-1.46 \mathrm{~mm}$, posterior margin: bregma $-2.00 \mathrm{~mm}$ ); the central nucleus of the amygdala (anterior margin: bregma $-0.94 \mathrm{~mm}$, posterior margin: bregma $-1.50 \mathrm{~mm}$ ); the medial amygdala (anterior margin: bregma $-1.6 \mathrm{~mm}$, posterior margin: bregma $-2.06 \mathrm{~mm}$ ); the supraoptic nucleus (SON) (anterior margin: bregma $-0.58 \mathrm{~mm}$, posterior margin: bregma $-0.94 \mathrm{~mm}$ ); the bed nucleus of the stria terminalis (anterior margin: bregma $0.62 \mathrm{~mm}$, posterior margin: bregma $0.02 \mathrm{~mm}$ ); the lateral septum (anterior margin: bregma $0.62 \mathrm{~mm}$, posterior margin: bregma $0.02 \mathrm{~mm}$ ); and the NTS (anterior margin: (bregma $-7.08 \mathrm{~mm}$, posterior margin: bregma $-8.24 \mathrm{~mm}$ ). All coordinates were obtained according to Paxinos and Franklin (2004) mouse brain atlas, with anatomical landmarks (e.g., white matter tracts) used as landmarks. Tissue punches were homogenized in lysis buffer provided by the RNAqueousMicro kit (Ambion, Invitrogen). RNA from adrenal gland, kidney, pituitary gland, and heart was isolated using RNeasy columns (QIAGEN), according to the manufacturer's instructions. DNase treatment (QIAGEN) was performed to minimize genomic DNA contamination of the RNA extract. Subsequently, cDNAs were synthesized with SuperScript III First-Strand Synthesis kit (Invitrogen) as described previously (Smith et al., 2014). Expression levels were evaluated by quantitative real-time PCR (qPCR) using a TaqMan 7900 Real time System with TaqMan Gene Expression Fast Master Mix and gene-specific TaqMan probes (Invitrogen). PCR primers were as follows: $\beta$-actin, $4352341 \mathrm{E}$ and Glp1r (Mm00445292.m1, primers spanning the deleted exons 6 and 7 ), as a target gene. Glp1r expression pattern was normalized to constitutively expressed $\beta$-actin, and relative expression pattern was quantified using the $\Delta \Delta$ method (Livak and Schmittgen, 2001).

RNAscope multiplex fluorescent assay. Double fluorescent RNAscope assay was performed on fresh-frozen brain tissues containing PVN collected from Sim 1-Cre, Glp $1 r^{\mathrm{f} / \mathrm{f}}$, and littermate Glp $1 r^{\mathrm{f} / \mathrm{f}}$ mice, according to the manufacturer's instructions with minor modification. The brains were collected and placed in a cryostat at $-20^{\circ} \mathrm{C}$ for $2 \mathrm{~h}$ to allow for temperature equilibration, and then sliced at a thickness of $12 \mu \mathrm{m}$. Sections were thaw-mounted onto Superfrost Plus slides. The slides were allowed to stand at $-20^{\circ} \mathrm{C}$ for $10 \mathrm{~min}$ and then stored at $-80^{\circ} \mathrm{C}$ until use. The fixation, protease digestion, probe hybridization, preamplification, amplification, and fluorescent labeling steps were performed according to the manufacturer's instructions (Advanced Cell Diagnostics). For detection of mRNA, a mouse Glp $1 r$ probe conjugated to Cy3 and Crh probe conjugated to AlexaFlour-488 sequences were custom-made by Advanced Cell Diagnostics using 6 ZZ pairs targeting the exons 6 and 7 of the Glp1r gene (NM_021332.2, 584-855) and 20 ZZ pairs targeting exon 2 of the Crh gene(NM_205769.2, 157-1262). Images were captured using AxioImager with Apotome, AxioCam Camera, Axio Vision Rel. 4.6 software (Carl Zeiss) at $63 \times$. Images were pseudo-colored ( $\mathrm{Crh}$, green; and Glp1r, red). mRNA signal, as represented by each punctate dot in the entire field of the image, was quantified using ImageJ (National Institutes of Health) software tool. Images were processed using ImageJ option "Despeckle" to remove single pixel background staining and then converted into binary images and skeletonized. The image was them analyzed using ImageJ "measure" tool. 
Table 1. Daily schedule for the CVS procedure (2 stressors/d; 2 weeks) ${ }^{a}$

\begin{tabular}{|c|c|c|c|c|c|}
\hline \multicolumn{3}{|c|}{ Week 1} & \multicolumn{3}{|c|}{ Week 2} \\
\hline Day & A.M. & P.M. & Day & A.M. & P.M. \\
\hline 1 & FST (10 min) & Cage rotation $(1 \mathrm{~h})$ & 8 & EPM (10 min) & Cold $\left(4^{\circ} \mathrm{C}, 1 \mathrm{~h}\right)$ \\
\hline 2 & EPM (5 min) & Hypoxia (30 min) & 9 & OF (5 min) & Hypoxia (30 min) \\
\hline 3 & OF (5 min) & Wet bedding $(1 \mathrm{~h})$ & 10 & Cage rotation (1 h) & Hypoxia (30 min) \\
\hline 4 & Cage rotation (1 h) & Cold $\left(4^{\circ} \mathrm{C}, 1 \mathrm{~h}\right)$ & 11 & Wet bedding $(1 \mathrm{~h})$ & Cold $\left(4^{\circ} \mathrm{C}, 1 \mathrm{~h}\right)$ \\
\hline 5 & EPM (5 min) & Hypoxia (30 min) & 12 & EPM $(5 \mathrm{~min})$ & Isolation housing $(0 / \mathrm{N})$ \\
\hline 6 & Wet bedding $(1 \mathrm{~h})$ & Cold $\left(4^{\circ} \mathrm{C}, 1 \mathrm{~h}\right)$ & 13 & Tilted cage $(0 / \mathrm{N})$ & Cage rotation $(1 \mathrm{~h})$ \\
\hline 7 & OF $(5 \mathrm{~min})$ & Tilted cage $(0 / \mathrm{N})$ & 14 & FST (10 min) & Hypoxia (30 min) \\
\hline
\end{tabular}

${ }^{a}$ The stressor types and duration are shown. $0 \mathrm{~F}$, Open field; $0 / \mathrm{N}$, overnight.

Basal HPA axis regulation. To assess basal circadian corticosterone levels, tail blood (15-20 $\mu \mathrm{l})$ samples from Sim1-Cre; Glp1r ${ }^{\mathrm{f} / \mathrm{f}}$ and littermate $\operatorname{Glplr}^{\mathrm{f} / \mathrm{f}}$ ( $n=9$ per group) mice were taken on two occasions, once during the A.M. at $0800 \mathrm{~h}$ (circadian nadir) and once during the P.M. (circadian peak) at $1500 \mathrm{~h}$. To test involvement of Sim1-Cre expression in basal HPA regulation, additional groups of Sim1-Cre and littermate $w t$ mice ( $n=9$ per group) were tested as above.

HPA axis regulation to acute stress. To assess HPA axis (ACTH and corticosterone) responses to an acute novel restraint challenge, mice [Sim1-Cre; Glp1r $r^{\mathrm{f} / \mathrm{f}}$ and littermates Glp $1 r^{\mathrm{f} / \mathrm{f}}(n=6$ per group)] were placed in well-ventilated $50 \mathrm{ml}$ conical tubes for 20 (for ACTH) or 30 (for corticosterone) min. For the analysis of ACTH concentrations, mice underwent rapid decapitation and trunk blood $(\sim 500 \mu \mathrm{l})$ was collected 20 min after restraint stress exposure. The restraint stress exposure for this particular experiment was limited to $20 \mathrm{~min}$ to allow us to capture peak stress-induced ACTH concentrations. The blood was stored and processed as described in the radioimmunoassay section. For analyzing corticosterone responses, tail blood samples were taken at 0 (prestress), 30, 60, and $120 \mathrm{~min}$ from Sim1-Cre; Glp1r ${ }^{\mathrm{f} / \mathrm{f}}$ and littermates $\operatorname{Glp}^{\mathrm{f}} \mathrm{r}^{\mathrm{f} / \mathrm{f}}(n=9$ per group). The 60 and 120 min time points were free-bleed poststress measures, as the mice had been removed from the restraint tubes and were placed back into the home cages. To preclude effects of Sim1-Cre transgene expression on stress reactivity, additional groups of Sim1-Cre and littermate $w t$ mice ( $n=7$ per group) were also tested, using an identical stress and sampling protocol. For assessment of corticosterone responses to a systemic stress, mice Sim1-Cre; Glp $1 r^{\mathrm{f} / \mathrm{f}}$ and littermate $\operatorname{Glp} 1 r^{\mathrm{f} / \mathrm{f}}(n=9$ per group) were placed in a clear Plexiglas chamber with clean bedding and exposed to $8 \%$ oxygen and $92 \%$ nitrogen for $30 \mathrm{~min}$. Tail blood samples were taken at 30,60, and $120 \mathrm{~min}$ after the initiation of hypoxia.

HPA axis regulation to chronic stress. Regulation of the HPA axis following chronic stress was determined in a separate set of Sim1-Cre; $G l p 1 r^{\mathrm{f} / \mathrm{f}}$ and littermate $G l p 1 r^{\mathrm{f} / \mathrm{f}}$ mice. Mice underwent a 2 week chronic variable stress (CVS) regimen or remained in their home cages for the duration of the experiment (no CVS controls). Thus, this experiment included four groups of male mice: no CVS Glp $1 r^{\mathrm{f} / \mathrm{f}}(n=7)$, CVS Glp $1 r^{\mathrm{f} / \mathrm{f}}$ $(n=7)$, no CVS Sim1-Cre; Glp1r ${ }^{\mathrm{f} / \mathrm{f}}(n=7)$, and CVS Sim1-Cre; Glp1r ${ }^{\mathrm{f} / \mathrm{f}}$ $(n=8)$. Mice in the CVS group were exposed to twice-daily randomly presented stressors with occasional overnight stressors (CVS regimen is described in Table 1). Body weight was assessed on a weekly basis. On the morning after completion of the CVS (day 15), all mice were given a novel restraint stress challenge for $30 \mathrm{~min}$. Mice were then overdosed with sodium pentobarbital and perfused. Adrenal and thymus glands were collected, cleaned, and weighed.

ACTH and corticosterone radioimmunoassay. Tail blood was collected into chilled EDTA-coated tubes. Plasma was separated by centrifugation at $4^{\circ} \mathrm{C} 6000 \mathrm{rpm}$ for $15 \mathrm{~min}$ and stored at $-20^{\circ} \mathrm{C}$. Tail blood samples were collected within 2 min from the initial handling of the mouse cage. Plasma corticosterone concentrations were determined using ${ }^{125}$ I radioimmunoassay kits (MP Biomedicals). Plasma ACTH concentrations were determined by a radioimmunoassay using a specific antiserum generously donated by Dr. William Engeland (University of Minnesota, Minneapolis) at a dilution of 1:120,000, with ${ }^{125}$ I ACTH (GE Healthcare) as a labeled tracer. All samples were run in duplicate, and all samples were run in the same assay. The intra-assay coefficient of variation was $<10 \%$ for both assays.
Tail blood glucose. Tail blood glucose level from freely moving mice was measured at, $0,30,60$, and 120 min following restraint and hypoxia using a Roche Accu-Check glucometer as described previously (Smith et al., 2014).

PVN Fos immunoreactivity. PFA-perfused brains from acutely stressed Sim1-Cre; Glp $1 r^{\mathrm{f} / \mathrm{f}}$ and littermates $G l p 1 r^{\mathrm{f} / \mathrm{f}}$ mice ( $n=6$ per group) were sectioned at $25 \mu \mathrm{m}$ and immunolabeled for Fos (1:2500; Santa Cruz Biotechnology, sc-52) using standard immunostaining procedures as described previously (Ghosal et al., 2014). The number of Fos-positive cells was counted bilaterally for each section and expressed as cells per unit area $\left(\mathrm{mm}^{2}\right)$. An observer blinded to the treatment conditions counted cells.

Radiotransmitter implantation and telemetric recording for cardiovascular studies. Mice [Sim1-Cre; Glp1r $r^{\mathrm{f} / \mathrm{f}}$ and littermates Glp $1 r^{\mathrm{f} / \mathrm{f}}(n=6-8$ per group)] were anesthetized with $2 \%$ isoflurane, vaporized with $100 \%$ oxygen. Telemetry devices (PA-C10, Data Sciences International) were implanted subcutaneously and anchored with suture to the abdominal muscle wall without occluding the animal's mobility. The catheter tip was inserted into the animals' left carotid artery in a way that it enters the aorta. Mice were allowed to recover for 2 weeks before the onset of the study followed by continuous recording of resting and stress-induced cardiovascular parameters (BP, HR, and locomotor activity). Following recovery from the telemetry surgery (2 weeks), Sim1-Cre; Glp1r ${ }^{\mathrm{f} / \mathrm{f}}$ and littermate $G l p 1 r^{\mathrm{f} / \mathrm{f}}$ mice were left undisturbed in their home cage for $7 \mathrm{~d}$. Resting mean arterial pressure (MAP), HR, and activity were recorded continuously, and were determined using A.R.T. Platinum software (DSI). These data were averaged as the mean values per hour over the entire day.

Cardiovascular responses to a novel acute restraint. For assessment of cardiovascular responses to a novel acute restraint, each mouse was placed into a restrainer (a well-ventilated $50 \mathrm{ml}$ conical plastic tube) for $30 \mathrm{~min}$. At the end of the $30 \mathrm{~min}$, mice were released from the restrainers into their home cages. The exact time at which mice were placed into the restrainer was considered the $0 \mathrm{~min}$ time point. Cardiovascular data were collected and analyzed before restraint (60 min during the morning before the test), throughout that restraint period $(30 \mathrm{~min})$, and throughout the recovery period ( $90 \mathrm{~min}$ after the restraint). HR, MAP, and locomotor activity were measured in $10 \mathrm{~min}$ bins. To determine the relative contribution of sympathetic versus parasympathetic nervous system in the stress-induced cardiovascular responses, pharmacological tests using propranolol ( $\beta$-adrenergic receptor antagonist, $4 \mathrm{mg} / \mathrm{kg}$, Sigma), atropine methyl nitrate (cholinergic receptor antagonist, $0.5 \mathrm{mg} / \mathrm{kg}$, Sigma), and hexamethonium (a ganglionic blocker, $0.2 \mathrm{mg} / \mathrm{kg}$, Sigma) were performed. The antagonists were given in the following order: (1) propranolol, (2) atropine methyl nitrate, and (3) hexamethonium. One week intervened between the three tests.

Elevated plus maze (EPM). Mice [Sim1-Cre; Glp1r $r^{\mathrm{f} / \mathrm{f}}$ and littermate $G l p 1 r^{\mathrm{f} / \mathrm{f}}$ were placed on a Plexiglas EPM apparatus for 5 min to assess anxiety-related behaviors. The EPM experiments were performed using two separate cohorts of mice ( $n=7-9$ per group/study). We first tested the baseline anxiety-like behaviors in nonstressed Sim 1-Cre; Glp1r ${ }^{\mathrm{f} / \mathrm{f}}$ and littermate $G l p 1 r^{\mathrm{f} / \mathrm{f}}$ mice. In the second EPM, we tested the anxiety-like behaviors in both genotypes following exposure to prior stressors (10 min swim and $1 \mathrm{~h}$ of rotation at $100 \mathrm{rpm}$ ). The EPM experiments were performed between 9:00 A.M. and 12:00 P.M. In this test, mice were placed in the center of the plus maze facing an open arm, and behavior 
A

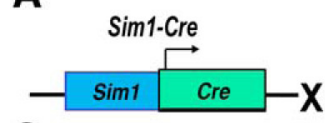

C

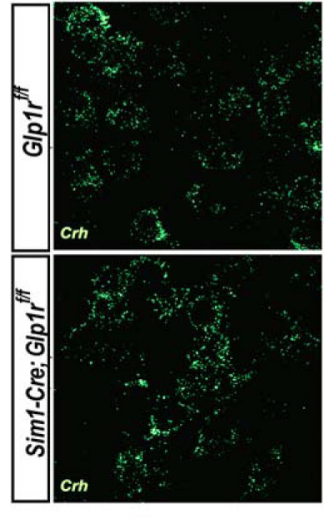

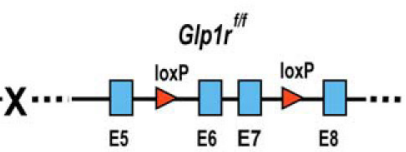
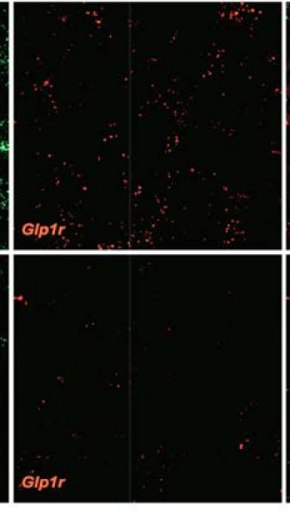
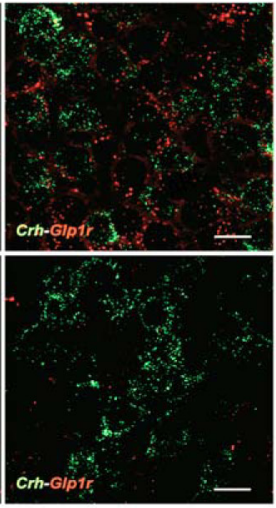

B

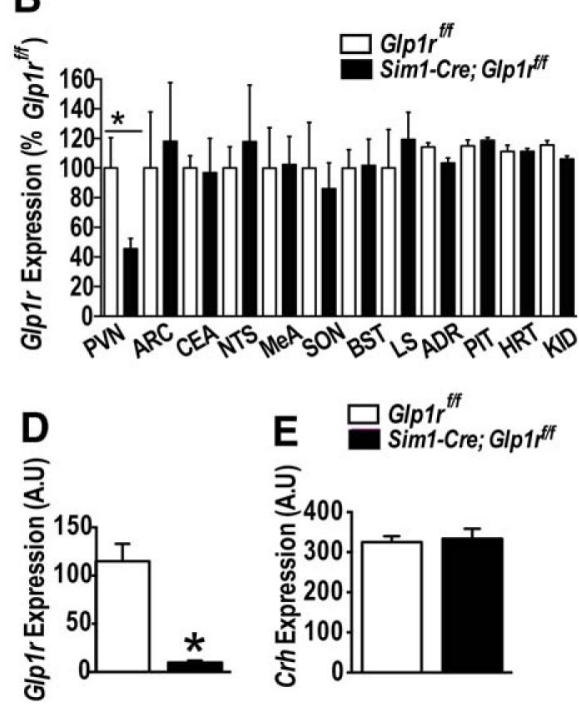

Figure 1. Sim1-Cre-induced KD of GIp1r within the PVN. $\boldsymbol{A}$, Genetic strategy to delete GIp 1r in neurons expressing Cre through the Sim 1 promoter. Mice carrying two conditional GIp1r alleles were crossed to the Sim1-Cre line to excise the exons 6 and 7 of the Glp1r gene. $B, G / p 1 r$ mRNA expression in various brain and peripheral tissues using primers specific for the amplicons spanning exons 6 and 7 in the Glp $1 r$ gene. The Sim 1-Cre; GIp 1r f/f mice showed $\sim 70 \%$ reduction in Glp1r mRNA expression within the PVN, but not in arcuate nucleus (ARC), central nucleus of amygdala (CEA), NTS, medial amygdala (MeA), SON, bed nucleus of stria terminalis (BST), lateral septum, pituitary (PIT), adrenal glands (ADR), heart (HRT), and kidney (KID). C, Representative images of RNAscope analysis of the GIp $1 r$ (red) and Crh (green) within the PVN Crh-enriched region of the GIp1r f/f (top) and Sim 1-Cre; GIp 1r ${ }^{\mathrm{f} / \mathrm{f}}$ (bottom). D, The expression of GIp1r mRNA was significantly reduced within the PVN Crh-enriched region of the Sim 1-Cre; Glp $1 r^{\mathrm{f} / \mathrm{f}}$ mice compared with $G 1 p 1 r^{\mathrm{f} / \mathrm{f}}$. $\boldsymbol{E}$, The expression of $\mathrm{Crh}$ was similar in both genotypes. Data are mean $\pm \mathrm{SEM}$. Scale bar: $\boldsymbol{C}, 20 \mu \mathrm{m}$. *

was recorded for the entire time period using an overhead mounted camera. Topscan software (Clever System) was used to measure time spent in the open and closed arm in the EPM, total distance traveled in the maze (locomotor activity), and number of entries into the open arm. The apparatus was thoroughly cleaned with $20 \%$ ethanol before each mouse was tested. Anxiety-related behavior is associated with less exploration of the open arm relative to overall exploration of all arms.

Forced swim test (FST). Mice [Sim1-Cre; Glp1r $\mathrm{r}^{\mathrm{f} / \mathrm{f}}$ and littermate $G l p 1 r^{\mathrm{f} / \mathrm{f}}$ ( $n=7$ or 8 per group)] were exposed to a cylinder ( $2 \mathrm{~L}$ glass beaker) filled with water $\left(23^{\circ} \mathrm{C}-25^{\circ} \mathrm{C}\right)$ for $10 \mathrm{~min}$. The FST was selected to assess depression-like behavior under naive conditions as well as following $14 \mathrm{~d}$ of CVS. The entire behavioral session was videotaped. Measured parameters included immobility (not making any active movement or floating in the water without struggling) and active behaviors (swimming). Time spent immobile was scored using Hindsight, Version 1.5 (Scott Weiss) as described previously (Ghosal et al., 2014). Behaviors were scored by an investigator blind to the experimental conditions.

Food intake studies. Anorectic effect of exendin-4 (Ex-4, GLP-1 receptor agonist) in Sim1-Cre; Glp $1 r^{\mathrm{f} / \mathrm{f}}$ and littermates Glp $1 r^{\mathrm{f} / \mathrm{f}}$ was tested as previously described (Smith et al., 2014). Mice [Sim1-Cre; Glp1r f/f and littermates $\operatorname{Glp}_{1} \mathrm{f}^{\mathrm{f} / \mathrm{f}}$ ( $n=9$ per group)] were fasted $4 \mathrm{~h}$ before the onset of dark phase. Ex-4 (Amylin Pharmaceuticals; $100 \mu \mathrm{g} / \mathrm{kg}$ ) or saline was injected into the peritoneum (i.p.) at the beginning of the dark phase, and food intake was measured after 1, 2, 4, 6, and $24 \mathrm{~h}$.

Body composition analysis. Body composition (lean mass and fat mass) was analyzed by MRI using a whole-body composition analyzer (EchoMedical Systems) as described previously (Sisley et al., 2014).

Statistical analysis. Data are expressed as mean \pm SEM. Sample sizes were based on previous hormonal and behavioral experiments in our laboratory. Student's $t$ tests were used for comparisons of two groups. Corticosterone, blood glucose, food intake, body weight, HR, blood pressure, locomotor activity, and FST data over multiple time points were analyzed using two-way or three-way repeated-measures ANOVA as appropriate (time being the repeated measure), followed by protected least significant difference post hoc analysis. Fisher's least significant difference was used for a priori planned comparisons across genotype and stress at each time point. Area under the curve, behavioral data (EPM), body composition data, RNAscope data, and immunoreactive cell counts were analyzed using Student's $t$ test. Data were analyzed using Sigma Stat (Systat) or Statistica (Statsoft) software. Statistical significance was set at $p \leq 0.05$. Data that did not fall in a normal distribution or equal variance were $\log$ transformed and reanalyzed.

\section{Results}

Sim1-Cre selective KD of the Glp1r mRNA expression within the PVN

We developed mice with PVN-directed Glp1r KD (Sim1-Cre; $\left.G l p 1 r^{\mathrm{f} / \mathrm{f}}\right)$ (Fig. 1A). Mice carrying Glp $1 r$ floxed allele $\left(G l p 1 r^{\mathrm{f} / \mathrm{f}}\right)$ (Smith et al., 2014) were crossed with mice expressing Crerecombinase in Sim1 neurons (Balthasar et al., 2005). Sim1 is a transcriptional factor that is highly expressed in the PVN. Sim1-Cre; Glp1r ${ }^{\mathrm{f} / \mathrm{f}}$ mice showed $\sim 70 \%$ reduction in Glp $1 r$ mRNA expression in the PVN region $\left(t_{(20)}=2.85, p<0.05 \mathrm{vs}\right.$ Glp1r ${ }^{\mathrm{f} / \mathrm{f}}$; Fig. 1B). Other brain areas that express Glp1r, including the central nucleus of amygdala, the medial amygdala, the SON, lateral septum, bed nucleus of the stria terminalis, the NTS, and the arcuate nucleus, showed no significant difference in Glp1r mRNA expression between Sim1-Cre; Glp $1 r^{\mathrm{f} / \mathrm{f}}$ and $G l p 1 r^{\mathrm{f} / \mathrm{f}}$ mice, demonstrating the expected regional specificity of the Sim1-Cre gene expression (Fig. 1B). Moreover, Glp1r mRNA expression was not significantly decreased in extra-CNS tissues (adrenal gland, pituitary, heart, or kidney) of Sim1-Cre; Glp1r ${ }^{\mathrm{f} / \mathrm{f}}$ mice (Fig. 1B).

To verify further Glp $1 r \mathrm{KD}$ and its relevance to the HPA axis at the level of the PVN, we used RNAscope fluorescent in situ hybridization to assess the following: (1) relative PVN Glp1r mRNA expression in Glp $1 r$ KD versus Glp1r ${ }^{\mathrm{f} / \mathrm{f}}$ animals; and (2) colocalization to corticotropin-releasing hormone neurons of the PVN. Fig. $1 C$ confirms that Glp1r mRNA is expressed within the Crhenriched region in the PVN of Glp $1 r^{\mathrm{f} / \mathrm{f}}$ mice and is markedly reduced in the comparable region of Sim 1-Cre; Glp $1 r^{\mathrm{f} / \mathrm{f}}$ mice (Fig. $1 C, D)$. The expression of $C r h$ mRNA expression was similar in both genotypes (Fig. 1E). These results verify efficiency Sim1Cre-mediated Glp1r mRNA KD at the cellular level and is consistent with the KD of mRNA by qPCR. 

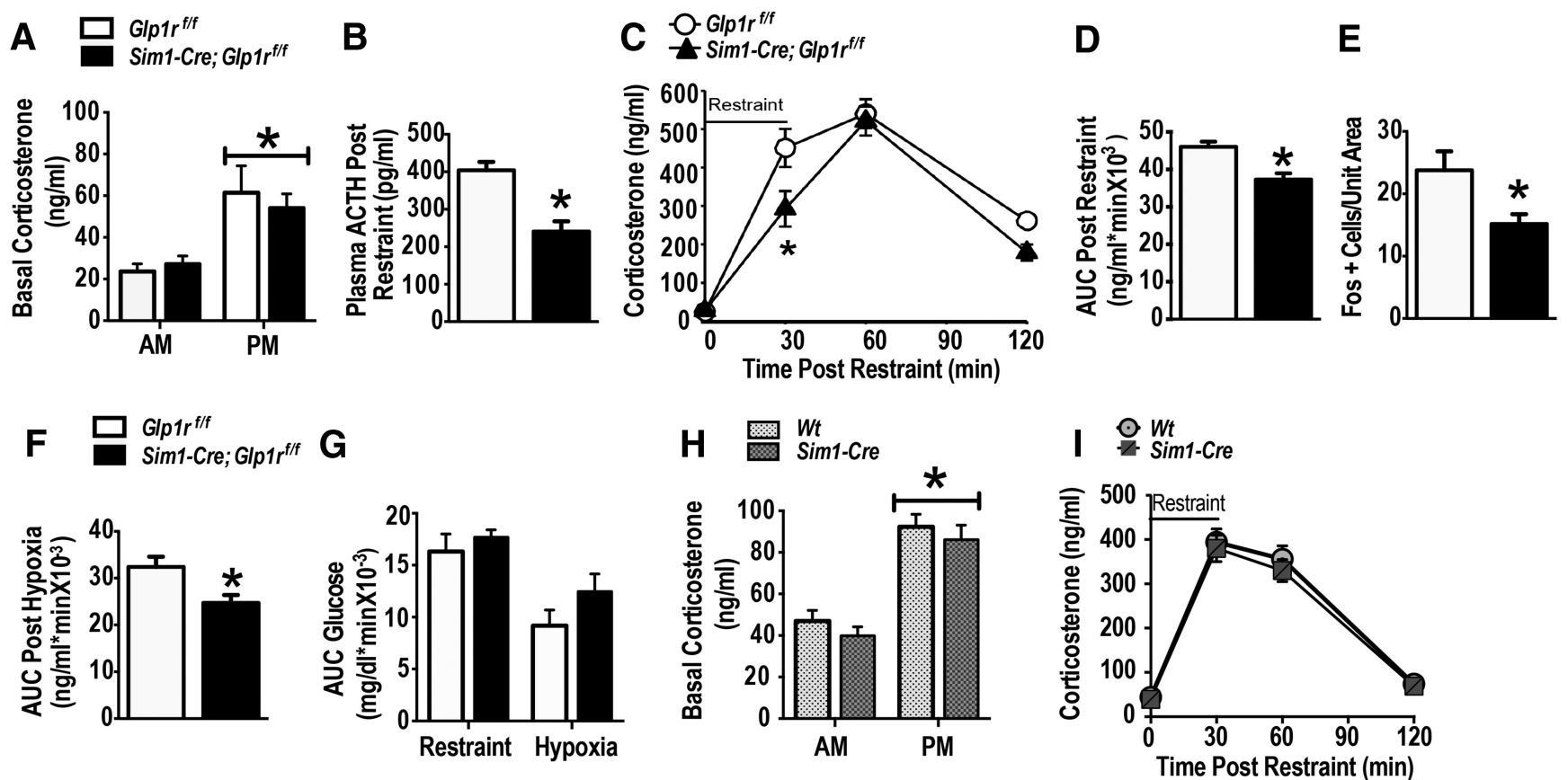

Figure 2. Sim 1-Cre-induced KD of Glp1r attenuates HPA axis responses to acute stress. A, Basal circadian nadir and peak corticosterone concentrations in Sim 1-Cre; Glp $1 r^{\mathrm{f} / \mathrm{f}}$ and Glp $1 r^{\mathrm{f} / \mathrm{f}} \mathrm{mice}$ ( $n=9$ per group). Both genotypes exhibited intact circadian regulation of corticosterone secretion. $\boldsymbol{B}$, Reduced peak ACTH response after a $20 \mathrm{~min}$ acute restraint stress in Sim 1-Cre; $\mathrm{Glp} 7 \mathrm{r}^{\mathrm{f} / \mathrm{f}} \mathrm{mice}$. C, Decreased corticosterone (time course) response to a novel 30 min restraint challenge in Sim 1-Cre; Glp1r/f mice. D, Reduced integrated corticosterone response in Sim 1-Cre; Glp $1 r^{\mathrm{f} / \mathrm{f}}$. E, Decreased

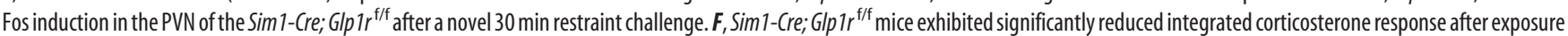
to a novel 30 min hypoxia (systemic stress). G, Blood glucose levels measured over the stress time-points during both acute restraint and hypoxia showed no significant differences between the two genotypes ( $n=9$ per group). $\boldsymbol{H}$, Basal nadir and peak corticosterone concentration in wild-type and Sim 1 -Cre mice showed no significant differences. There were significant differences between P.M. corticosterone level and A.M. corticosterone in both genotypes $(p<0.05)$, but no genotype-related differences $(n=7$ per group). $I$, The time course of the corticosterone response to a 30 min restraint challenge did not differ between the two genotypes. Data are mean \pm SEM. ${ }^{*} p<0.05 \mathrm{vs} \mathrm{Glp} 1 \mathrm{r} f / f$.

\section{Glp1r KD in Sim1 neurons attenuates neuroendocrine} response to acute stress

Sim1-Cre; Glp1r $r^{\mathrm{f} / \mathrm{f}}$ and Glp $1 r^{\mathrm{f} / \mathrm{f}}$ mice were tested for basal (circadian) HPA axis regulation and responses to acute stress. There was no difference in peak or nadir corticosterone concentrations between Sim1-Cre; Glp1r ${ }^{\mathrm{f} / \mathrm{f}}$ and Glp $1 r^{\mathrm{f} / \mathrm{f}}$ mice, indicating an intact diurnal HPA axis rhythm (Fig. $2 A)\left(F_{(1,35)}=40.24, p<0.001 \mathrm{vs}\right.$ A.M., $n=9$ per group). To test the necessity of PVN Glp1 $r$ for the HPA axis regulation during acute stress, Sim1-Cre; Glp1r ${ }^{\mathrm{f} / \mathrm{f}}$ and $G l p 1 r^{\mathrm{f} / \mathrm{f}}$ littermates were subjected to restraint stress, a common test used to assess psychogenic stress responses (Furay et al., 2008). The plasma ACTH response to restraint was reduced in Sim1-Cre; Glp1r ${ }^{\mathrm{f} / \mathrm{f}}$ mice (Fig. $\left.2 B\right)\left(t_{(10)}=4.616, p<0.001 \mathrm{vs}\right.$ $G l p 1 r^{\mathrm{f} / \mathrm{f}}, n=6$ per group), consistent with GLP-1-mediated activation of the HPA axis. Similarly, both time course (Fig. 2C) and integrated area under the curve (Fig. 2D) plasma corticosterone responses were significantly diminished in the Sim1-Cre; Glp $1 r^{\mathrm{f} / \mathrm{f}}$ mice relative to $G l p 1 r^{\mathrm{f} / \mathrm{f}}$ littermates $\left(F_{(3,71)}=156.84\right.$, main effect of time, $p<0.05 ; F_{(1,71)}=7.76$ main effect of genotype, $p<0.05$; $F_{(3,71)}=3.00, p<0.05$, time $\times$ genotype interaction; Fig. $2 C$; $t_{(16)}=-3.47, p<0.003$, vs Glp1r $r^{\mathrm{f} / \mathrm{f}}$; Fig. $\left.2 D\right)$. PVN neuronal activation in the Sim1-Cre: Glp $1 r^{\mathrm{f} / \mathrm{f}}$ mice following restraint, assessed by Fos expression, was also significantly reduced $\left(t_{(10)}=\right.$ 2.50, $p<0.05$ vs Glp1r ${ }^{\mathrm{f} / \mathrm{f}}$; Fig. $2 E$ ), consistent with decreased PVN drive in the absence of PVN GLP-1 signaling. We next tested whether diminished HPA axis responses in the Sim1-Cre; Glp $1 r^{\mathrm{f} / \mathrm{f}}$ was generalizable to other stress modalities. PVN KD and control littermates were exposed to hypoxia ( $8 \%$ oxygen) for $30 \mathrm{~min}$. Hypoxia-induced corticosterone responses were significantly reduced in the Sim1-Cre; Glp1r ${ }^{\mathrm{f} / \mathrm{f}}$ mice $\left(t_{(16)}=-2.51, p<0.02 \mathrm{vs}\right.$ Glp1r ${ }^{\mathrm{f} / \mathrm{f}}$; Fig. $\left.2 F\right)$. Brain GLP-1 signaling has been reported to regulate glucose metabolism (Ghosal et al., 2013). Notably, in response to restraint stress or hypoxia, there was no difference in blood glucose between the PVN Glp $1 r$ KD and control mice (Fig. $2 G)$, suggesting that neuronal Glp1 projections to the PVN are not required for regulation of glucose homeostasis under the specific conditions tested. Importantly, we did not observe disruption of circadian corticosterone secretion or enhanced HPA axis responses to restraint in mice carrying the Sim1-Cre transgene on a wild-type background (Fig. $2 \mathrm{H}, \mathrm{I}$ ), confirming that alterations in HPA axis function are due to Sim1-directed Glp1r KD rather than the presence of the Sim1-Cre transgene alone. Collectively, these data indicate that GLP-1 signaling in the PVN is essential for full activation of the HPA axis during psychogenic as well as physiologic stress, and mediated by a circuit distinct from those controlling glucose regulation.

\section{Glp1r KD in the Sim1 neurons attenuates neuroendocrine} response to chronic stress

To investigate a potential role for PVN GLP-1 signaling in key physiological responses to chronic stress, we subjected Sim1-Cre; Glp $1 r^{\mathrm{f} / \mathrm{f}}$ and Glp $1 r^{\mathrm{f} / \mathrm{f}}$ littermates to a 2 week CVS regimen (Table 1) or maintained them under standard housing conditions (no CVS). The CVS paradigm is a well-characterized model of chronic stress in rodents that produces physiological (attenuated weight gain), neuroendocrine (HPA axis facilitation), and behavioral adaptations (anxiety- and depression-related behaviors) (Furay et al., 2008). We observed a CVS-induced reduction of body weight during week 1 of CVS in both genotypes $\left(F_{(1,25)}=\right.$ $37.90, p<0.05$ vs no CVS; Fig. $3 A$ ). However, during week 2 , the CVS-exposed Sim1-Cre; Glp1r $r^{\mathrm{f} / \mathrm{f}}$ mice showed significantly less body weight loss than CVS-exposed $\operatorname{Glp} 1 r^{\mathrm{f} / \mathrm{f}}$ mice $\left(F_{(1,25)}=5.19\right.$, 

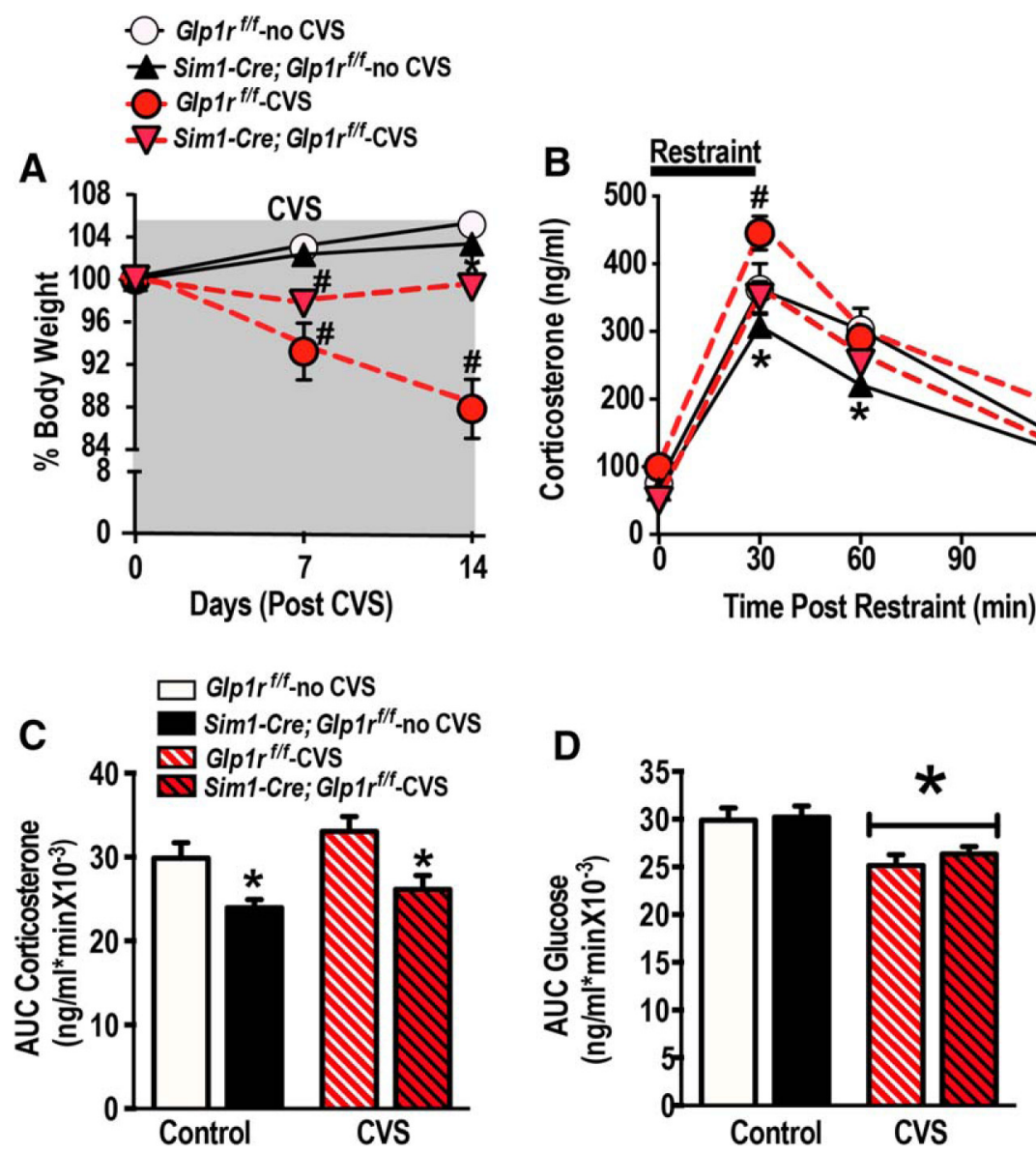

Figure 3. GLP-1 receptor KD diminishes chronic stress responses. A, CVS caused a significant reduction in percentage body weight in both Sim 1-Cre; Glp 1r $r^{\mathrm{fff}}$ and GIp $1 r^{\mathrm{f} / \mathrm{f}}$ during week 1. ${ }^{\#} p<0.05$ versus respective no CVS control. After week 1, Sim 1-Cre; Glp $1 r^{f / f}$ displayed significantly less body weight loss relative to $G / p 1 r^{f / f}$ CVS-exposed mice. "Significant difference from respective no CVS control. *Significant difference from Glp $1 r^{\mathrm{f} / \mathrm{f}}$-CVS exposed mice. $\boldsymbol{B}, \boldsymbol{C}$, Time course $(\boldsymbol{B})$ and integrated corticosterone response $(\boldsymbol{C})$ to a novel $30 \mathrm{~min}$ restraint challenge in Glp1r/f and Sim 1-Cre; Glp $1 r^{\mathrm{f} / \mathrm{f}}$ mice. Statistical analysis revealed that CVS GIp $1 r^{\mathrm{fff}}$ mice had significantly higher corticosterone response than no CVS GIp1r ${ }^{\mathrm{f} / \mathrm{f}}$. CVS Sim 1-Cre; Glp $1 r^{\mathrm{f} / \mathrm{f}}$ mice showed significantly decreased corticosterone at the $30 \mathrm{~min}$ time point compared with CVS G/p $7 r^{\mathrm{flf}}$ mice. There were no significant differences between the CVS-exposed and no CVS Sim 1-Cre; GIp $1 r^{\mathrm{f} / \mathrm{f}}$ in the corticosterone response. Regardless of the CVS assignment, integrated stress response to restraint stress was significantly reduced in the Sim 1 -Cre; Glp $1 r^{\mathrm{f} / \mathrm{f}}$ compared with Glp $1 r^{\mathrm{f} / \mathrm{f}}$. "Significant difference from respective no CVS control. * ${ }^{*}$ ignificant difference from respective $\mathrm{Glp} 1 r^{\mathrm{f} / \mathrm{f}}$. $\boldsymbol{D}$, Integrated glucose response to a novel 30 min restraint challenge in $\mathrm{Glp} 1 \mathrm{r}^{\mathrm{f} / \mathrm{f}}$ and $\mathrm{Sim} 1-\mathrm{Cre} ; \mathrm{Glp} 1 \mathrm{r}^{\mathrm{f} / \mathrm{f}}$ mice showed no effect of genotype. However, there was a main effect of stress, and area under the curve glucose was reduced in both genotypes following CVS exposure. *Significant difference from respective no CVS controls. Data are mean \pm SEM.

$p<0.05$ vs Glp1r ${ }^{\mathrm{f} / \mathrm{f}}$-CVS; Fig. 3A), suggesting that GLP-1 signaling may contribute to weight loss observed in rodent as a consequence of chronic stress. Importantly, Sim1-Cre; Glp $1 r^{\mathrm{f} / \mathrm{f}}$ and littermates $G l p 1 r^{\mathrm{f} / \mathrm{f}}$ did not differ in body weight at the outset of the study (Table 2), indicating that Glp1r KD by itself has no effect on body weight under nonstressed conditions. To assess HPA axis facilitation following chronic stress, Sim1-Cre; Glp $1 r^{\mathrm{f} / \mathrm{f}}$ and littermates $G l p 1 r^{\mathrm{f} / \mathrm{f}}$ were submitted to a novel acute restraint stress, with plasma corticosterone levels as the primary outcome measure (Fig. $3 B$ ). We found that the corticosterone response to novel stress was increased in CVS-exposed Glp1r $r^{\mathrm{f} / \mathrm{f}}$ mice relative to non-CVS controls $\left(F_{(3,75)}=208.36 ; p<0.05\right.$, main effects of time; $F_{(1,25)}=17.82 ; p<0.05$, main effects of genotype; Figure $3 B)$, consistent with expected stress facilitation of the HPA axis (Bhatnagar and Dallman, 1998). In contrast, CVS did not affect the magnitude of the novel stress responses in the Sim1-Cre; Glp1 $r^{\mathrm{f} / \mathrm{f}}$ group $(p<0.05$; Fig. $3 B, C)$, suggesting that GLP-1 signaling is required for chronic stress sensitization of the HPA axis.
Again, despite the observed differences in HPA axis stress responses, there were no significant differences in blood glucose levels among the genotypes (Fig. 3D).

\section{PVN Glp1r signaling is required for stress-induced cardiovascular responses}

To investigate whether PVN Glp1rexpressing neurons also contribute to sympathetic nervous system cardiovascular responses to acute stress, HR and MAP were measured under resting and stressed conditions in Sim1-Cre; Glp $1 r^{\mathrm{f} / \mathrm{f}}$ and $G l p 1 r^{\mathrm{f} / \mathrm{f}}$ littermate controls using radiotelemetry. Baseline studies showed that both Sim1-Cre; Glp1r ${ }^{\mathrm{f} / \mathrm{f}}$ and controls showed similar circadian patterns of cardiovascular function (Fig. $4 A-C)\left(F_{(1,29)}\right.$ $=112.29 ; p<0.05$, main effects of time; Fig. $4 A ; F_{(1,29)}=186.19 ; p<0.05$, main effects of time; Fig. $4 C$ ). In contrast, following a novel restraint $(30 \mathrm{~min})$ stress, $\operatorname{MAP}\left(F_{(1,52)}=34.54, p<0.05\right.$ vs Glp1 $r^{\mathrm{f} / \mathrm{f}}$; Fig. $4 D, E)$ and $\operatorname{HR}\left(F_{(1,52)}=13.30, p<\right.$ 0.05 vs $G l p 1 r^{\mathrm{f} / \mathrm{f}}$; Fig. $\left.4 F, G\right)$ responses were significantly attenuated in Sim1-Cre;

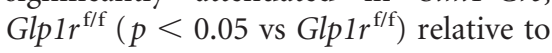
their littermate controls. There were no differences in general locomotion. To assess the mechanism of Glp1r action, cardiovascular stress responses were measured during autonomic blockade. Propranolol (a nonselective $\beta$-adrenergic receptor antagonist) decreased HR to a lesser extent in Sim1-Cre; Glp1r ${ }^{\mathrm{f} / \mathrm{f}}$ mice compared with control $(p<0.05$; Fig. $4 H)$. In contrast, no genotype differences were observed after parasympathetic blockade with atropine (a cholinergic muscarinic receptor antagonist) (Fig. $4 H)$. Finally, there was no difference between the genotypes in the increase in HR (Fig. 4I) following total ganglionic (autonomic) blockade, suggesting that the intrinsic properties of the heart were not altered by Glp1r KD. Together, these results indicate that PVN Glp1r signaling enhances stress-induced HR responses predominantly through activation of sympathetic drive to the heart.

\section{Sim1 Glp1r KD reduces anxiety-like behaviors}

Behavioral responses are an important part of adaptation to stress. To determine the effect of PVN GLP-1R on behavioral stress responses, stress-naive Sim1-Cre; Glp $1 r^{\mathrm{f} / \mathrm{f}}$ mice and their littermate $G l p 1 r^{\mathrm{f} / \mathrm{f}}$ controls were tested in an EPM. In addition, for the assessment of stress-induced behavioral reactivity, a separate cohort of Sim1-Cre; Glp $1 r^{\mathrm{f} / \mathrm{f}}$ mice and their littermate Glp $1 r^{\mathrm{f} / \mathrm{f}}$ controls were exposed to stressors (FST and rotation) on the day before the EPM testing. The Sim 1-Cre; Glp1r ${ }^{\mathrm{f} / \mathrm{f}}$ mice spent more time in the open arm of the EPM $\left(t_{(16)}=4.50, p<\right.$ 0.05 vs $G l p 1 r^{\mathrm{f} / \mathrm{f}}$; Fig. $5 A$ ) compared with littermates $G l p 1 r^{\mathrm{f} / \mathrm{f}}$ controls. Moreover, increased time in the open arm was also observed in mice exposed to prior stressors $\left(t_{(12)}=2.70\right.$, 
Table 2. Initial body weight, adrenal weight and thymus weight of Glp1 $\mathrm{r}^{\mathrm{f} / \mathrm{f}}$ and Sim1-Cre; Glp1r ${ }^{f / f}$ mice with or without a history of chronic stress.

\begin{tabular}{|c|c|c|c|c|}
\hline & \multicolumn{2}{|l|}{ NoCVS } & \multicolumn{2}{|l|}{ CVS } \\
\hline & $G \mid p 1 r^{f / f}$ & $\begin{array}{l}\text { Sim1-Cre; } \\
\text { Glp1r/f/f }\end{array}$ & $G 1 p 1 r^{f / f}$ & $\begin{array}{l}\text { Sim1-Cre; } \\
\text { Glp1r/f/f }\end{array}$ \\
\hline $\begin{array}{l}\text { Initial BW }(\mathrm{g}) \\
\text { Normalized adrenal } \\
\quad\left(\mathrm{mg} / 100 \mathrm{~g}^{*} \text { body }\right.\end{array}$ & $26.88 \pm 1.14$ & $27.55 \pm 1.16$ & $28.76 \pm 0.75$ & $28.84 \pm 0.88$ \\
\hline $\begin{array}{l}\text { weight) } \\
\text { Normalized thymus } \\
\text { (mg/100g*body }\end{array}$ & $0.008 \pm 0.001$ & $0.012 \pm 0.001$ & $0.011 \pm 0.001$ & $0.010 \pm 0.001$ \\
\hline weight) & $0.13 \pm 0.03$ & $0.12 \pm 0.02$ & $0.13 \pm 0.01$ & $0.13 \pm 0.02$ \\
\hline
\end{tabular}

$p<0.05$ vs Glp1r f/f; Fig. 5B), suggesting a resistance phenotype of the Sim 1-Cre; Glp1r ${ }^{\mathrm{f} / \mathrm{f}}$ mice to the impact of prior stress on anxiety-like responses. There was no significant effect of Glp1r KD on forced swim behavior (either acutely or following $1 \mathrm{~d}$ of CVS), measured as the time spent in the immobility behavior measuring immobility duration (Fig. $5 C$ ), suggesting the selectivity of Glp1r signaling for anxiety-related behaviors, but not behavioral despair. Notably, there were no differences in total distance traveled in the EPM, indicating that differences in activity do not account for behavioral changes (Fig. 5D).

\section{Sim1-Cre Glp1r KD does not alter food intake, and body composition in the absence of experimental stress}

GLP-1 signaling in the brain regulates both energy and glucose homeostasis (Barrera et al., 2011). Thus, it is possible that metabolic actions of GLP-1 may modulate stress endpoints. To determine whether Sim1-mediated Glp1r KD disrupts resting metabolic function, $24 \mathrm{~h}$ food intake was measured in Sim1-Cre; $G l p 1 r^{\mathrm{f} / \mathrm{f}}$ and Glp $1 r^{\mathrm{f} / \mathrm{f}}$ mice fed either chow or high fat diet. No differences were noted in $24 \mathrm{~h}$ food intake ( $p>0.05 \mathrm{vs} G l p 1 r^{\mathrm{f} / \mathrm{f}}$; Fig. 6A) during exposure to either diet, indicating that PVN Glp $1 r$ signaling is not necessary for the regulation of food intake under these conditions. Because Glp1r agonists are known to reduce food intake (Kinzig et al., 2003), the response to Ex-4, a Glp1r agonist, was assessed in chow-fed mice. Acute administration of Ex-4 reduced food intake in both cohorts $(p<0.05$ vs saline controls; Fig. $6 B$ ) but was independent of Sim1-Cre Glp1r KD ( $p>0.05$ vs Glp1r ${ }^{\mathrm{f} / \mathrm{f}}$; Fig. 6C). Similarly, there were no differences in body weight or body composition (fat mass and lean mass) between the Sim1-Cre; Glp1 $r^{\mathrm{f} / \mathrm{f}}$ and Glp1 $r^{\mathrm{f} / \mathrm{f}}$ mice (Fig. 6C). These data suggest that Glp1r signaling is not required for aspects of energy homeostasis tested in our experiments. These data are in contrast with efficacy of PVN Glp $1 r$ KD in prevention of chronic stress-induced weight loss, suggesting that the latter effect is driven by modulations of stress response magnitude at the level of the PVN.

\section{Discussion}

The results here provide direct evidence that GLP-1, a peptide neurotransmitter with CNS production largely limited to the hindbrain (Campbell and Drucker, 2013), is necessary in the coordination of physiological as well as behavioral responses to stress. Here, we used PVN-targeted Glp1r KD to demonstrate the intimate relationship between PVN GLP-1 signaling and physiologic and emotional reactivity to stress. Mice lacking the Glp $1 r$ in the PVN have reduced HPA axis responses to both acute and chronic stress, show reduced chronic stress facilitation of HPA axis responses, and display reduced anxiety-like behavior as as- sessed in the EPM, both under basal conditions and following prior stress exposure. Moreover, Glp1r KD attenuated stressinduced cardiovascular responses, associated with decreased sympathetic drive to the heart. Finally, Glp $1 r$ KD mice were protected against chronic stress-induced body weight loss. These data indicate that a monosynaptic connection between NTS GLP-1 neurons and GLP-1-receptive neurons in the PVN is required for appropriate integration of the whole-organism response to both acute and chronic stress.

\section{Putative role of GLP-1 signaling in PVN Sim1-positive neurons in mediating multiple aspects of general stress integration}

Establishing the mechanism of action of GLP-1 on stress reactivity has been confounded by uncertainty about the extent to which gut-derived GLP-1 in the circulation crosses the blood-brain barrier to influence CNS functions (Kanoski et al., 2011), and the possibility of indirect effects from peripheral GLP-1 systems (Heppner et al., 2015). Consequently, results from studies of mice with global knock-out of the Glp1r are difficult to interpret (Scrocchi et al., 1996; MacLusky et al., 2000). In this study, we used targeted KD of Glp1r in the PVN, a central hypothalamic node mediating stress responses as well as a major target of NTS proglucagon neuronal projections (Merchenthaler et al., 1999; Vrang et al., 2007). Similar to the effectiveness of the Sim1-Cre mouse line to $\mathrm{KD}$ or rescue other target genes in the PVN (Balthasar et al., 2005; Solomon et al., 2015), Sim1-Cre; Glp1r ${ }^{\mathrm{f} / \mathrm{f}}$ mice exhibited tissue-specific reduction of Glp1r mRNA expression by both qPCR and RNAscope cellular localization.

In addition to robust expression in PVN, Sim1 is expressed in the SON, medial amygdala, posterior hypothalamic nuclei, premammillary nucleus, and nucleus of the lateral olfactory tract (Balthasar et al., 2005). Moreover, a recent study using reporter mice demonstrates, in addition to high density of GLP-1 receptor expression throughout the hypothalamus, GLP-1 receptor is also expressed in bed nucleus of stria terminalis, lateral septum, and medial and basolateral amygdala (Cork et al., 2015). Therefore, to rule out an impact of altered Glp1r expression in these brain regions on the phenotype observed, we performed qPCR-based assessments in micropunches obtained from known Glp1rexpressing regions implicated in stress regulation. With the exception of the PVN, we observed no significant difference in Glp1r expression compared with wild-type littermates. (We were somewhat surprised by the lack of a significant downregulation in the SON but feel this is likely due to dilution of circular punches with neighboring Glp1r-expressing regions, such as the medial amygdala). Moreover, there is limited evidence of a significant direct role for the GLP-1 signaling in these brains regions in autonomic or behavioral stress responses. These data are supported by a recent comprehensive study characterizing the expression of Glp1r in the monkey and rat using in situ hybridization, ligand binding, and immunocytochemistry, which revealed minimal expression in the majority of Sim1-expressing regions, including the medial amygdala, ventromedial hypothalamus, and lateral/dorsal hypothalamus (Heppner et al., 2015). Therefore, it is unlikely that the results of our studies are the result of deletion of GLP-1R in regions other than the PVN. Thus, the PVN stands out as the most likely mediator of the reduced stress phenotype in the Sim1-Cre; Glp1r ${ }^{\mathrm{f} / \mathrm{f}}$ mice.

Although striking that the general physiologic endpoint of weight loss predictably during CVS is largely reversed in the Sim1cre-Glp1r ${ }^{\mathrm{f} / \mathrm{f}}$ mice, other aspects of energy homeostasis tested in our experiments appear to be less affected. The data suggest 

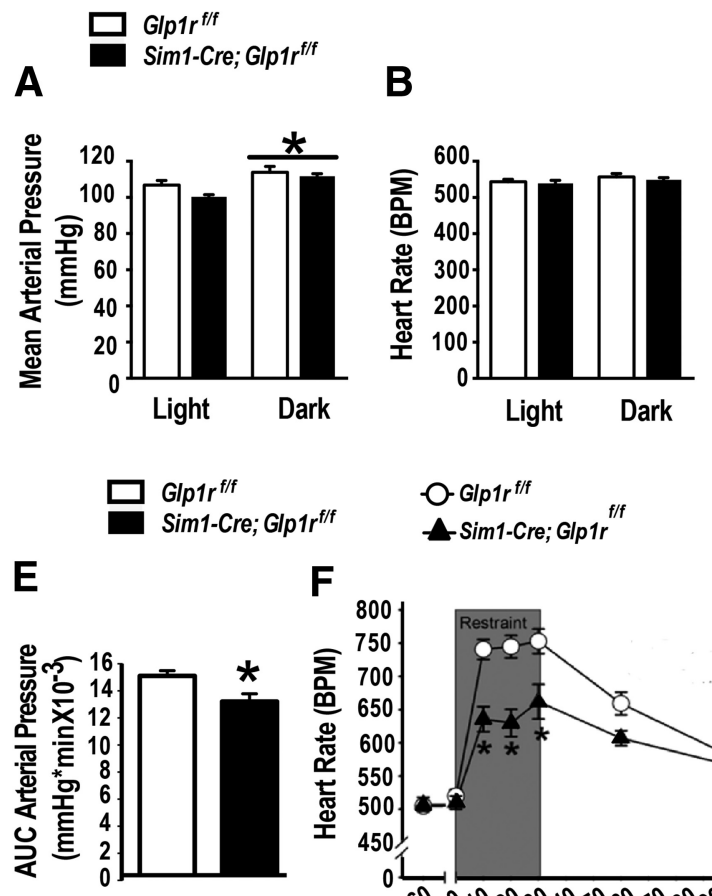

$\mathbf{F}$

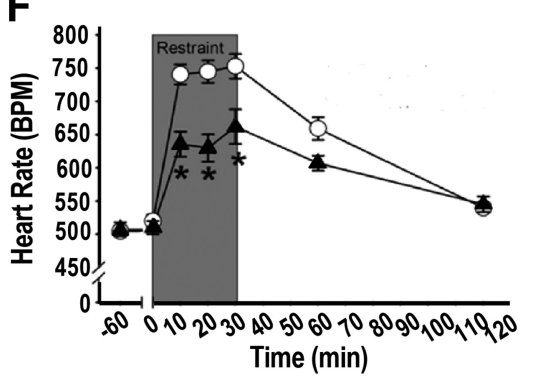

C

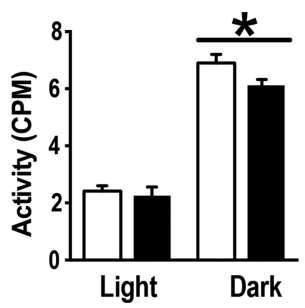

G

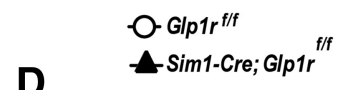

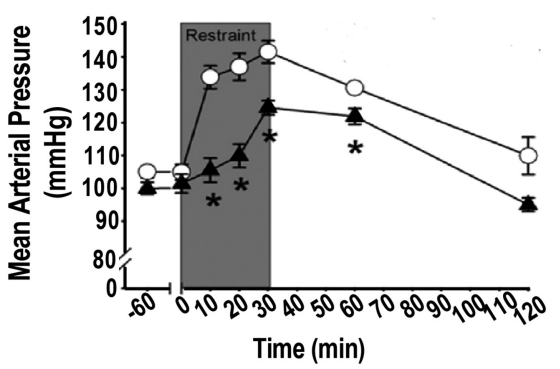

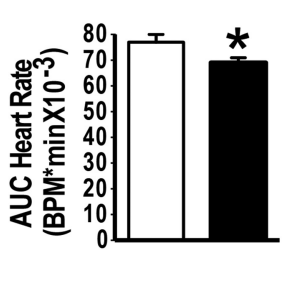

H

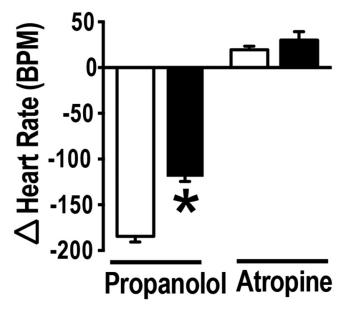

I

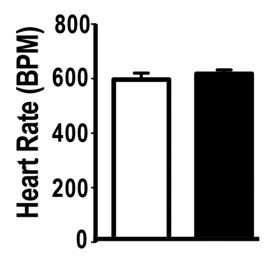

Figure 4. Sim1-Cre Glp1r KD attenuates cardiovascular responses to acute restraint. $\boldsymbol{A}-\boldsymbol{C}$, Baseline recordings of blood pressure $(\boldsymbol{A})$, HR $(\boldsymbol{B})$, and total activity $(\boldsymbol{C})$ revealed no significant differences between the genotypes. There were main effects of time on blood pressure and activity, consistent with known circadian patterns. $D-G$, Exposure to acute restraint induced significant increases in blood pressure (MAP) and HR (BPM) that were attenuated in Sim 1-Cre; GIp $1 r^{\mathrm{f} / \mathrm{f}}$ mice. * Significant difference from Glp $1 r^{\mathrm{f} / \mathrm{f}}\left(n=7\right.$ or 8 per group). H, Sim 1-Cre; GIp $1 r^{\mathrm{f} / \mathrm{f}}$ mice showed less sympathetic cardiac tone following restraint, but there was no difference in the parasympathetic drive to the heart. $I$, HR response following total ganglionic blockade with hexamethonium did not differ between the genotypes. Data are mean \pm SEM.

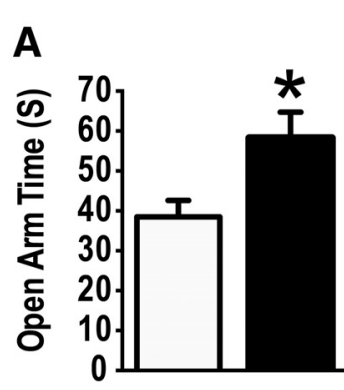

B

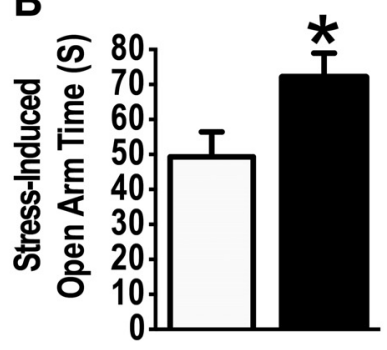

C

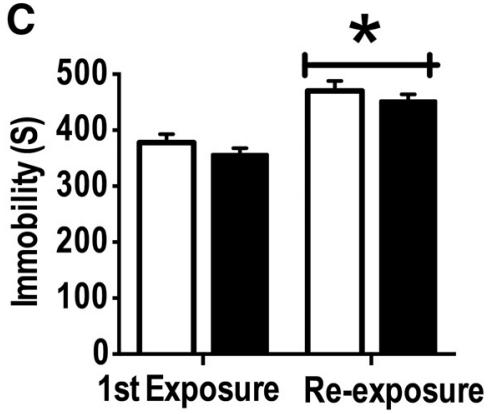

Glp1rtit

Sim1-Cre; Glp1 $r^{\text {ft }}$

Figure 5. Decreased anxiety-like behavior following KD of Glp $1 r$ in $\operatorname{Sim} 1$ neurons. A, Sim 1-Cre; Glp $1 r^{\mathrm{f} / \mathrm{f}}$ mice exhibited more open arm time in the EPM than their littermates Glp $1 r^{\mathrm{f} / \mathrm{f}}$ under basal conditions. $\boldsymbol{B}, \operatorname{Sim} 1-\mathrm{Cre}$; Glp1r ${ }^{\mathrm{f} / \mathrm{f}}$ exhibited increased exploration into the open arm following prior stress exposure (10 min FST $+1 \mathrm{~h}$ rotation on a platform shaker on the day before testing). ${ }^{*}$ Significant difference from GIp $1 r^{\mathrm{f} / \mathrm{f}}$. C, There was no significant effect of Glp $1 \mathrm{r}$ KD on immobility in the FST. D, There was no genotype difference in locomotion in the EPM.

that stress effects through regions in which Glp1r is reduced by Sim 1cre, including those on body weight, are mediated by specific pathways that are largely independent of GLP-1 effects on energy balance in unstressed animals. This conclusion is consistent with a recent study indicating that central GLP-1 contributes predominantly to the ability of acute psychological stressor to inhibit food intake but has no effect on baseline food intake in the absence of stress (Maniscalco et al., 2015). Furthermore, it is tempting to speculate that primary effects of GLP-1 on metabolism may be mediated by receptors in other brain regions. Indeed, many studies have identified other brains regions, including the ventral tegmental area (Alhadeff and Grill, 2014), nucleus accumbens
(Dossat et al., 2011), hippocampus (Kanoski and Grill, 2015), parabrachial nucleus (Swick et al., 2015), and NTS (Barrera et al., 2011) are sufficient for mediating central GLP-1-/Ex-4-induced suppression of food intake and for regulation of energy homeostasis.

Preferential role of Sim1 GLP-1 signaling in mediating anxiety-like but not depression-like behaviors

In the current study, we noted a preferential involvement of the Sim1-Cre-induced decreased Glp1r signaling in mediating anxiety-like behavior, but not depression-like behavior, suggesting specific anxiolytic effects of PVN Glp1r deletion, at least as 


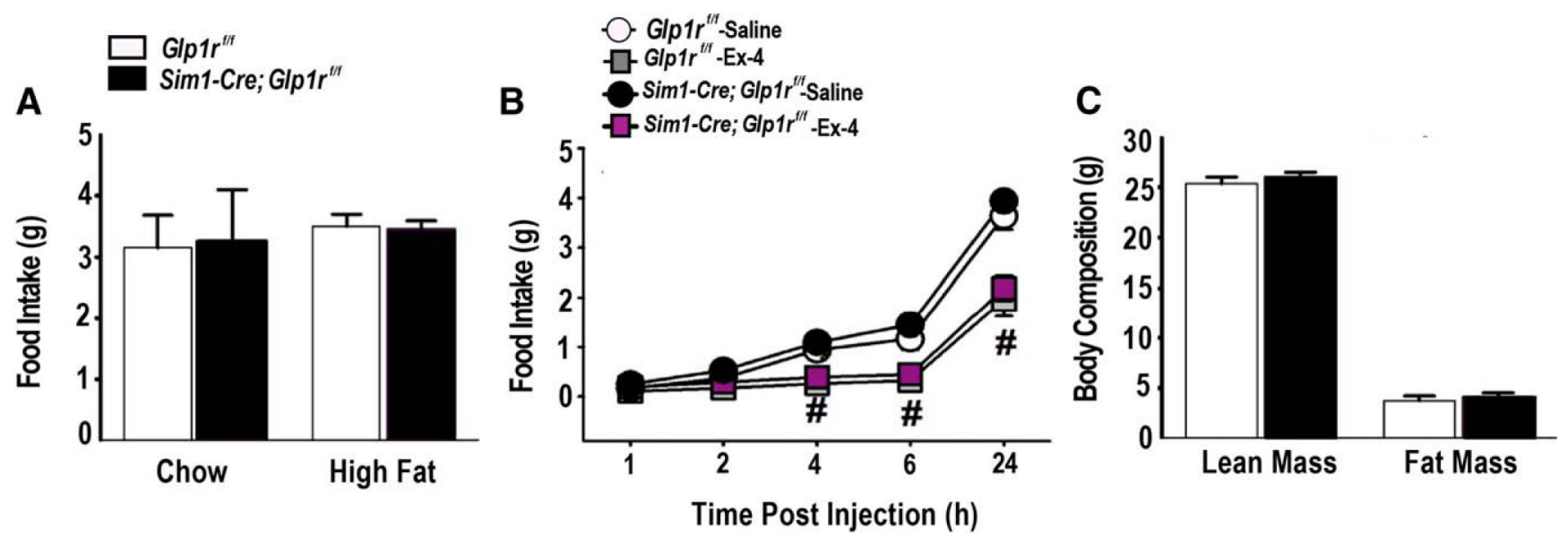

Figure 6. Sim 1-Cre GIp 1r KD does not alter food intake or body weight in the absence of stress. A, There were no significant genotype differences in food intake (under either normal chow or high-fat diet conditions). B, There were no genotype effects in response to the GIp1r agonist Ex-4. " Significant difference from respective saline control ( $n=7$ or 8 per group). C, Body composition showed no significant difference between the two genotypes ( $n=7$ or 8 per group).

assessed in the EPM. Although PVN involvement in HPA axis and cardiovascular regulation is known, it is not commonly implicated in behavioral stress responses. However, prior studies indicate that lesions of the PVN can reduce behavioral indices of arousal (Herman et al., 1991), and recent evidence suggests that PVN neurons project to forebrain regions implicated in emotional regulation (e.g., medial and central amygdaloid nuclei) (Knobloch et al., 2012), suggesting a possible role in anxiogenesis. Alternatively, sympatho-excitation can be accompanied by activation of central systems that promote anxiety responses. Given that Sim 1-Cre-directed Glp1r KD reduces peripheral sympathetic responses, this impaired signaling may also constrain central pathways activated by, or occurring in tandem with, peripheral responses. The lack of Glp1r KD and/or significant Glp1r expression in the medial and central amygdala makes it unlikely that the decrease in anxiety-like behavior is due to altered GLP1R signaling in these regions.

In the current study, anxiety-like behavior was assessed in the EPM. Although this test captures passive versus exploratory aspects of anxiety, it is not sufficient to fully define an "anxious" phenotype (better assessed with multiple tests), and we therefore limit our interpretation to this test. However, it is important to note that expression of anxiety-like behaviors (e.g., increased open arm time) replicated across two cohorts tested under different conditions, supporting the reproducibility of the EPM findings.

\section{Autonomic substrate of the Sim1 GLP-1-mediated cardiovascular responses}

Attenuated stress-induced blood pressure and HR responses in Sim1-Cre; Glp1r $1 r^{\mathrm{f} / \mathrm{f}}$ mice was at least in part due to reduced sympathetic drive to the heart, as evidenced by attenuated bradycardia following blockade of sympathetic drive. This is consistent with observations that intracerebroventircular GLP-1 administration activates sympathetic preganglionic neurons in autonomic control sites, increasing HR and blood pressure (Yamamoto et al., 2002, 2003). Moreover, preganglionic neurons receive direct projections from GLP-1-expressing cell groups in the brainstem and GLP-1receptive PVN neurons, consistent with a role of endogenous GLP-1 in autonomic activation (Isbil-Buyukcoskun and Gulec, 2004). The altered cardiovascular responses in our study were robust and have potentially important clinical implications. A variety of therapeutic agents manipulating GLP-1 activity (e.g., long-acting GLP-1 agonists) and inhibitors of dipeptidyl-peptidase 4 are now being used in the treatment of diabetes and diabetes-related obesity (Zoicas et al., 2013). Of particular concern is that long-acting GLP-1 agonists may penetrate into the CNS to exert untoward effects on autonomic controlled cardiovascular functions. Infusions of GLP- 1 or Ex- 4 into the CNS show increased blood pressure and increased HR (Yamamoto et al., 2002), and human studies reveal a small but significant increase in HR in patients treated with either Ex-4 or liraglutide (Buse et al., 2009). Our Sim1-Cre mouse studies suggest a mechanism whereby GLP-1 agonists may have cardiovascular effects in the context of stress, a possibility that warrants further investigation.

In conclusion, together, our study suggests that GLP-1 neurons projecting to the PVN from the NTS have a unique and essential function in adaptation to both acute and chronic stress. The importance of GLP-1 in global stress integration suggests that it may play a role in pathologies characterized by dysregulation of multiple stress systems, such as depression (enhanced HPA axis activity, cardiovascular pathology, comorbid anxiety) and post-traumatic stress disorder (decreased HPA axis activity, autonomic over-reactivity, anxiety). Moreover, GLP-1 receptor agonists, acting both peripherally and centrally, are widely used in treatment of Type II diabetes, necessitating consideration of central stress-excitatory actions of GLP-1 as a potential complicating factor for chronic treatment.

\section{References}

Alhadeff AL, Grill HJ (2014) Hindbrain nucleus tractus solitarius glucagonlike peptide-1 receptor signaling reduces appetitive and motivational aspects of feeding. Am J Physiol 307:R465-R470. CrossRef Medline

Balthasar N, Dalgaard LT, Lee CE, Yu J, Funahashi H, Williams T, Ferreira M, Tang V, McGovern RA, Kenny CD, Christiansen LM, Edelstein E, Choi B, Boss O, Aschkenasi C, Zhang CY, Mountjoy K, Kishi T, Elmquist JK, Lowell BB (2005) Divergence of melanocortin pathways in the control of food intake and energy expenditure. Cell 123:493-505. CrossRef Medline

Barrera JG, Jones KR, Herman JP, D’Alessio DA, Woods SC, Seeley RJ (2011) Hyperphagia and increased fat accumulation in two models of chronic CNS glucagon-like peptide-1 loss of function. J Neurosci 31:3904-3913. CrossRef Medline

Bhatnagar S, Dallman M (1998) Neuroanatomical basis for facilitation of hypothalamic-pituitary-adrenal responses to a novel stressor after chronic stress. Neuroscience 84:1025-1039. CrossRef Medline

Buse JB, Rosenstock J, Sesti G, Schmidt WE, Montanya E, Brett JH, Zychma 
M, Blonde L (2009) Liraglutide once a day versus exenatide twice a day for type 2 diabetes: a 26-week randomised, parallel-group, multinational, open-label trial (LEAD-6). Lancet 374:39-47. CrossRef Medline

Campbell JE, Drucker DJ (2013) Pharmacology, physiology, and mechanisms of incretin hormone action. Cell Metab 17:819-837. CrossRef Medline

Carter JR, Goldstein DS (2015) Sympathoneural and adrenomedullary responses to mental stress. Compr Physiol 5:119-146. CrossRef Medline

Chrousos GP, Gold PW (1992) The concepts of stress and stress system disorders: overview of physical and behavioral homeostasis. JAMA 267: 1244-1252. CrossRef Medline

Cork SC, Richards JE, Holt MK, Gribble FM, Reimann F, Trapp S (2015) Distribution and characterisation of Glucagon-like peptide-1 receptor expressing cells in the mouse brain. Mol Metab 4:718-731. CrossRef Medline

de Kloet ER, Joëls M, Holsboer F (2005) Stress and the brain: from adaptation to disease. Nat Rev Neurosci 6:463-475. CrossRef Medline

Dossat AM, Lilly N, Kay K, Williams DL (2011) Glucagon-like peptide 1 receptors in nucleus accumbens affect food intake. J Neurosci 31:1445314457. CrossRef Medline

Furay AR, Bruestle AE, Herman JP (2008) The role of the forebrain glucocorticoid receptor in acute and chronic stress. Endocrinology 149:54825490. CrossRef Medline

Ghosal S, Myers B, Herman JP (2013) Role of central glucagon-like peptide-1 in stress regulation. Physiol Behav 122:201-207. CrossRef Medline

Ghosal S, Bundzikova-Osacka J, Dolgas CM, Myers B, Herman JP (2014) Glucocorticoid receptors in the nucleus of the solitary tract (NTS) decrease endocrine and behavioral stress responses. Psychoneuroendocrinology 45:142-153. CrossRef Medline

Grippo AJ (2009) Mechanisms underlying altered mood and cardiovascular dysfunction: the value of neurobiological and behavioral research with animal models. Neurosci Biobehav Rev 33:171-180. CrossRef Medline

Heppner KM, Kirigiti M, Secher A, Paulsen SJ, Buckingham R, Pyke C, Knudsen LB, Vrang N, Grove KL (2015) Expression and distribution of glucagon-like peptide- 1 receptor mRNA, protein and binding in the male nonhuman primate (Macaca mulatta) brain. Endocrinology 156:255267. CrossRef Medline

Herman JP, Thomas GJ, Wiegand SJ, Gash DM (1991) Lesions of parvocellular subdivisions of the hypothalamic paraventricular nucleus alter open field behavior and acquisition of sensory and spatial discrimination. Brain Res 550:291-297. CrossRef Medline

Herman JP, McKlveen JM, Ghosal S, Kopp B, Wulsin A, Makinson R, Scheimann J, Myers B (2016) Regulation of the hypothalamic-pituitaryadrenocortical stress response. Compr Physiol 6:603-621. CrossRef Medline

Isbil-Buyukcoskun N, Gulec G (2004) Effects of intracerebroventricularly injected glucagon-like peptide- 1 on cardiovascular parameters: role of central cholinergic system and vasopressin. Regul Pept 118:33-38. CrossRef Medline

Kanoski SE, Grill HJ (2015) Hippocampus contributions to food intake control: mnemonic, neuroanatomical, and endocrine mechanisms. Biol Psychiatry piiS0006-3223(15)00771-4.

Kanoski SE, Fortin SM, Arnold M, Grill HJ, Hayes MR (2011) Peripheral and central GLP-1 receptor populations mediate the anorectic effects of peripherally administered GLP-1 receptor agonists, liraglutide and exendin-4. Endocrinology 152:3103-3112. CrossRef Medline

Kinzig KP, D’Alessio DA, Herman JP, Sakai RR, Vahl TP, Figueiredo HF, Murphy EK, Seeley RJ, Figueredo HF (2003) CNS glucagon-like peptide-1 receptors mediate endocrine and anxiety responses to interoceptive and psychogenic stressors. J Neurosci 23:6163-6170. Medline

Knobloch HS, Charlet A, Hoffmann LC, Eliava M, Khrulev S, Cetin AH, Osten P, Schwarz MK, Seeburg PH, Stoop R, Grinevich V (2012) Evoked axonal oxytocin release in the central amygdala attenuates fear response. Neuron 73:553-566. CrossRef Medline
Livak KJ, Schmittgen TD (2001) Analysis of relative gene expression data using real-time quantitative PCR and the 2(T)(-Delta Delta C) method. Methods 25:402-408. CrossRef Medline

MacLusky NJ, Cook S, Scrocchi L, Shin J, Kim J, Vaccarino F, Asa SL, Drucker DJ (2000) Neuroendocrine function and response to stress in mice with complete disruption of glucagon-like peptide-1 receptor signaling. Endocrinology 141:752-762. CrossRef Medline

Maniscalco JW, Zheng H, Gordon PJ, Rinaman L (2015) Negative energy balance blocks neural and behavioral responses to acute stress by "silencing” central glucagon-like peptide 1 signaling in rats. J Neurosci 35: 10701-10714. CrossRef Medline

Merchenthaler I, Lane M, Shughrue P (1999) Distribution of pre-proglucagon and glucagon-like peptide-1 receptor messenger RNAs in the rat central nervous system. J Comp Neurol 403:261-280. CrossRef Medline

Paxinos G, Franklin K (2004) The mouse brain in stereotaxic coordinates, Ed 4. San Diego: Elsevier/Academic.

Scrocchi LA, Brown TJ, MaClusky N, Brubaker PL, Auerbach AB, Joyner AL, Drucker DJ (1996) Glucose intolerance but normal satiety in mice with a null mutation in the glucagon-like peptide 1 receptor gene. Nat Med 2:1254-1258. CrossRef Medline

Sisley S, Gutierrez-Aguilar R, Scott M, D'Alessio DA, Sandoval DA, Seeley RJ (2014) Neuronal GLP1R mediates liraglutide's anorectic but not glucose-lowering effect. J Clin Invest 124:2456-2463. CrossRef Medline

Smith EP, An Z, Wagner C, Lewis AG, Cohen EB, Li B, Mahbod P, Sandoval D, Perez-Tilve D, Tamarina N, Philipson LH, Stoffers DA, Seeley RJ, D'Alessio DA (2014) The role of beta cell glucagon-like peptide-1 signaling in glucose regulation and response to diabetes drugs. Cell Metab 19:1050-1057. CrossRef Medline

Solomon MB, Loftspring M, de Kloet AD, Ghosal S, Jankord R, Flak JN, Wulsin AC, Krause EG, Zhang R, Rice T, McKlveen J, Myers B, Tasker JG, Herman JP (2015) Neuroendocrine function after hypothalamic depletion of glucocorticoid receptors in male and female mice. Endocrinology 156:2843-2853. CrossRef Medline

Swick JC, Alhadeff AL, Grill HJ, Urrea P, Lee SM, Roh H, Baird JP (2015) Parabrachial nucleus contributions to glucagon-like peptide-1 receptor agonist-induced hypophagia. Neuropsychopharmacology 40:2001-2014. CrossRef Medline

Tauchi M, Zhang R, D’Alessio DA, Stern JE, Herman JP (2008) Distribution of glucagon-like peptide-1 immunoreactivity in the hypothalamic paraventricular and supraoptic nuclei. J Chem Neuroanat 36:144-149. CrossRef Medline

Ulrich-Lai YM, Herman JP (2009) Neural regulation of endocrine and autonomic stress responses. Nat Rev Neurosci 10:397-409. CrossRef Medline

Varndell IM, Bishop AE, Sikri KL, Uttenthal LO, Bloom SR, Polak JM (1985) Localization of glucagon-like peptide (Glp) immunoreactants in human gut and pancreas using light and electron-microscopic immunocytochemistry. J Histochem Cytochem 33:1080-1086. CrossRef Medline

Vrang N, Hansen M, Larsen PJ, Tang-Christensen M (2007) Characterization of brainstem preproglucagon projections to the paraventricular and dorsomedial hypothalamic nuclei. Brain Res 1149:118-126. CrossRef Medline

Yamamoto H, Lee CE, Marcus JN, Williams TD, Overton JM, Lopez ME, Hollenberg AN, Baggio L, Saper CB, Drucker DJ, Elmquist JK (2002) Glucagon-like peptide-1 receptor stimulation increases blood pressure and heart rate and activates autonomic regulatory neurons. J Clin Invest 110:43-52. CrossRef Medline

Yamamoto H, Kishi T, Lee CE, Choi BJ, Fang H, Hollenberg AN, Drucker DJ, Elmquist JK (2003) Glucagon-like peptide-1-responsive catecholamine neurons in the area postrema link peripheral glucagon-like peptide-1 with central autonomic control sites. J Neurosci 23:2939-2946. Medline

Zoicas F, Droste M, Mayr B, Buchfelder M, Schöfl C (2013) GLP-1 analogues as a new treatment option for hypothalamic obesity in adults: report of nine cases. Eur J Endocrinol 168:699-706. CrossRef Medline 